\title{
PACTO adolescentes: arte e corpo na invenção de dispositivos em terapia ocupacional para produção de vida e saúde na adolescência
}

\author{
The youth group of PACTO: art and body on the \\ invention of devices in occupational therapy to the \\ production of life and health in adolescence
}

\author{
Elizabeth Maria Freire de Araújo Lima ${ }^{1}$, Daniela Figueiredo \\ Canguçu $^{2}$, Christiana Moraes ${ }^{3}$, Erika Alvarez Inforsato ${ }^{4}$
}

\begin{abstract}
LIMA, E. M. F. de A.; CANGUÇU, D. F.; MORAES, C. INFORSATO, E. A. PACTO adolescentes: arte e corpo na invenção de dispositivos em terapia ocupacional para produção de vida e saúde na adolescência. Rev. Ter. Ocup. Univ. São Paulo, v. 20, n. 3, p. 157-163, set./dez. 2009.
\end{abstract}

\begin{abstract}
RESUMO: O artigo apresenta o trabalho desenvolvido no grupo de adolescentes do Programa Permanente de Composições Artísticas e Terapia Ocupacional (PACTO), que se constituiu em campo de experimentação e pesquisa em intervenção grupal com população heterogênea, com jovens advindos de realidades sócio-econômicas diversificadas e apresentando diferentes necessidades e problemáticas. A discussão focaliza a proposta desenvolvida nos anos de 2002 e 2003, numa parceria entre terapeutas ocupacionais e artistas plásticos e/ou arte-educadores, que participaram da concepção, planejamento e invenção de um dispositivo de acionamento de novos lugares sociais e de projetos de vida e saúde, permitindo uma ampliação da oferta de recursos no acompanhamento de trajetórias singulares. Os resultados deste trabalho apontam para a construção de uma metodologia de intervenção na interface da terapia ocupacional com as artes, que pressupõe um alinhamento rigoroso entre criação artística, produção de vida e de subjetividade. Através de um diálogo com a arte contemporânea, esta metodologia busca explorar modos particulares de relação com objetos do cotidiano e novas ordenações destes materiais, de modo a propor um novo sentido para o olhar da própria vida.
\end{abstract}

DESCRITORES: Terapia Ocupacional/tendências. Arte. Terapia pela arte/tendências. Adolescente.

${ }^{1}$ Docente do Curso de Terapia Ocupacional do Departamento de Fisioterapia, Fonoaudiologia e Terapia Ocupacional da FMUSP.

2 Terapeuta ocupacional do Centro de Atenção Psicossocial Luis da Rocha Cerqueira (CAPS-Itapeva/ UNIFESP).

3 Artista, coordenadora dos Núcleos Educativos do Museu da Imagem e do Som (MIS) e do Paço das Artes da USP.

4 Terapeuta ocupacional do Curso de Terapia Ocupacional do Departamento de Fisioterapia, Fonoaudiologia e Terapia Ocupacional da FMUSP.

Endereço para correspondência: Rua Cipotânea, 51 CEP: 05508-900 - São Paulo / SP. E-mail: beth.lima@usp.br 


\section{INTRODUÇÃO}

$\mathrm{D}$ urante seis anos, de 1998 a 2003, desenvolvemos uma trajetória de encontros com um grupo que denominamos PACTOAdolescentes. Este grupo constituiu-se em campo de formação, pesquisa e desenvolvimento de metodologia de intervenção com grupos de composição heterogênea na interface da Terapia Ocupacional (TO) com as artes.

O grupo, formado por jovens advindos de realidades sócio-econômicas diversas e apresentando diferentes necessidades e problemáticas, caracterizou-se por um desenho que permitiu múltiplas composições e um número que variou entre 6 e 13 integrantes. Estes chegavam ao grupo para participar de ateliês de corpo e arte, encaminhados por serviços de saúde, centros de juventude, escolas especiais, ou por demanda espontânea; podiam se inserir no trabalho a qualquer momento do processo (desde que o grupo tivesse vaga) e permaneciam no grupo por um período variável, de acordo com as necessidades, os projetos singulares e o processo grupal.

A equipe de coordenação contou com terapeutas ocupacionais, estagiários e bolsistas dos campos das artes e da TO e, a partir de 2002, com uma artista plástica e arteeducadora da Divisão de Ensino e Ação Cultural do Museu de Arte Contemporânea da USP (MAC USP).

De início organizamos o trabalho de forma a configurar dois momentos, separados por uma pausa para o café: um momento no qual realizávamos propostas de sensibilização e expressão corporal e outro, no qual trabalhávamos com diferentes linguagens e técnicas artísticas. Nos encontros que se davam semanalmente durante um período de 3 horas, trabalhamos com pintura, desenho de observação, fotografia e mosaico; e com massagens, toques, jogos teatrais e danças. O objetivo dessa proposta era criar um campo de experimentação das linguagens artísticas e das dimensões variadas e complexas da convivência coletiva, que pudesse se constituir em dispositivo ${ }^{1}$ de acionamento de novos lugares sociais e de projetos de vida e saúde.

Os encontros foram fotografados, filmados e registrados em Caderno de Relato do grupo, o que possibilitou o acompanhamento do processo e a realização de pesquisas.

\section{ADOLESCÊNCIA: ALGUNS APONTAMENTOS}

Quando iniciamos o trabalho, nosso aporte contava com alguns norteadores para pensar a adolescência. Estas noções-guia não se baseavam na idade cronológica, mas na presença de algumas questões na experiência existencial de uma criança que começa a crescer: as transformações do corpo e da imagem corporal; a emergência da sexualidade genital; as demandas que o grupo social passa a fazer em relação às posições que se deve assumir; a preocupação com uma futura profissão ou trabalho que possa ser desenvolvido; o estranhamento com respeito a essas transformações. Para Rodolpho Rufino, "o instante que põe em marcha a adolescência se dá a alguém quando ele se vê convocado, desde o seu corpo e desde o olhar do outro, a ser algo diferente do que a criança" (RUFFINO, 1995, p. 41).

Infância e vida adulta: etapas que dividem e organizam o processo vital. Em "Micropolítica e Segmentariedade", Deleuze e Guattari nos dizem que somos segmentarizados por todos os lados e em todas as direções.

A segmentariedade pertence a todos os estratos que nos compõem. Habitar, circular, trabalhar, brincar (...) somos segmentarizados binariamente, a partir de grandes oposições duais: as classes sociais, mas também os homens e as mulheres, os adultos e as crianças, etc (DELEUZE; GUATTARI, 1996, p. 83).

A oposição entre o adulto e a criança carrega muitas outras oposições: natureza e cultura, dependência e independência, tutela e responsabilidade, mundo do brinquedo e mundo do trabalho. $\mathrm{O}$ mundo da infância $\mathrm{e}$ o da vida adulta parecem estar tão separados que alguns autores referem-se à necessidade de se viver uma morte na passagem de um a outro, caracterizada pela adolescência. Essa vivência da morte de um modo de ser se expressaria no grande número de suicídios nesta fase da vida e se presentificaria, de forma simbólica, na violência que participa dos ritos de passagem nas sociedades tradicionais (DOLTO, 1990).

A adolescência seria, então, um lugar de passagem entre um e outro mundo, quando não se está nem num nem noutro ou se está nos dois ao mesmo tempo; um lugar híbrido, no qual aquilo que foi desenvolvido pode desviar. Além de lugar de passagem, a adolescência é hoje objeto de estudo e constitui por si um novo segmento, definido justamente pela "movência", pelo trânsito. Se a infância e a vida adulta podem ser tomadas como lugares de repouso - já que há uma expectativa de funcionamento normal dos sujeitos nessas fases da vida -, a adolescência é o lugar do movimento e da crise $^{2}$. Do adolescente se espera que não se

\footnotetext{
${ }^{1}$ Regina Benevides de Barros (1997) toma o termo de Deleuze, na leitura que este autor faz de Foucault, para pensar o grupo como um dispositivo, algo que põe em ação e faz funcionar.
} 
submeta às exigências sociais, que seja questionador, que não se adapte facilmente, que crie caso, que experimente crises. Como afirma Ana Freud,

No que concerne à adolescência, parece mais fácil descrever suas manifestação patológicas do que os processos normais. (...) a adolescência é, por sua natureza, uma interrupção do crescimento pacífico e a sustentação de um equilíbrio constante durante o processo de adolescência é em si anormal (FREUD, 1995, p. 82).

A passagem e o desvio passam, assim, a constituir um novo segmento. Os adolescentes constituem, cada vez com mais força, um grupo distinto com características próprias e seu próprio sistema de referência. Neste sentido, a adolescência passa de uma definição negativa (não é aquilo nem isso) para uma positivação: "entre duas leis, a criança brinca e o adulto trabalha, a adolescência é o momento de uma tentação nômade" (RASSIAL, 1995, p. 25).

A instituição da adolescência nesses termos instaura, no processo de crescimento normal, um período de mobilidade e nomadismo autorizado e com duração limitada. Depois é preciso encontrar uma forma estável, trabalhar/produzir, casar/reproduzir. Cubides et al. (1998) falam em moratória social para designar um período de tempo livre socialmente legitimado, postergando-se assim a assunção de responsabilidades econômicas e sociais.

A saúde e o desenvolvimento normal ficam associados à superação desse período, quando se atingiria o equilíbrio, a estabilidade e uma identidade bem constituída, pois se hoje todas as formas se desmancham rapidamente, os territórios existenciais se desfazem com grande rapidez, tudo circula apenas para ficar no mesmo lugar, já que tudo é intercambiável (GUATTARI, 1994). Neste contexto, em que a subjetividade fica ameaçada de petrificar-se, aquilo que não é identidade ou fixidez passa a exercer uma enorme atração, apontando para a tendência de alargamento do período da adolescência. O que é possível observar na recusa ou no adiamento de se ingressar no mundo adulto, por vezes na busca de se poder ainda experimentar períodos de movência; outras, por não se encontrar nesse mundo abertura ou espaço para nele ingressar.

\section{OS ADOLESCENTES DO GRUPO DO PACTO}

$$
\text { A atuação no PACTO-adolescentes nos fez }
$$

problematizar os norteadores que tínhamos para pensar a adolescência, ao nos confrontar com experiências que de alguma forma estavam colocadas sob esta insígnia, mas que não se ajustavam às expectativas e definições a ela relacionadas.

Para os jovens que freqüentavam o PACTO as questões da adolescência se apresentavam de forma ainda mais complexa. Os participantes nos colocavam frente ao desafio de promover uma experiência de grupalidade que não passasse por identificações segmentarizadas: jovens que haviam passado por situações de adoecimento grave, de miséria ou violência, que apresentavam sofrimento psíquico, deficiência física ou mental, se encontravam em um espaço de experimentação corporal e plástica no qual ligações inusitadas e vínculos sutis eram engendrados.

Como pensar a adolescência de pessoas que não correspondem aos modelos subjetivos disponíveis? Adultos em corpos de crianças; crianças em corpos de adultos ou existências para sempre infantilizadas. Para cada um, expectativas e demandas muito diferentes daquelas que Ruffino (1995) identifica como disparadores do processo adolescente. De alguns não se espera que cresçam, como um dos participantes do grupo, de 24 anos, considerado pela família "uma criança normal como todas as outras". Outros foram desde sempre impulsionados a um mundo adulto que não os queria, mulheres e homens em corpos de criança, como na história de outra integrante, de 17 anos, grávida de seu segundo filho. Ou ainda aqueles que a eminência de uma doença grave retirou a abertura de futuro característica dessa fase da vida ${ }^{3}$, como a participantes que teve uma das pernas amputadas devido a um câncer do qual estava se tratando.

Designar este grupo como PACTO-adolescentes, mais do que classificar, teve como efeito introduzir questões da adolescência ou nomear certas inquietações como sendo da ordem desse acontecimento. Possibilitou também para os coordenadores enxergar uma dinâmica adolescente nos ritmos, nas brincadeiras, nas formas como se relacionavam.

Mas, para trabalhar com esses jovens foi preciso fazer um deslocamento, para que a movência deixasse de estar localizada em um momento da trajetória vital, e passasse a ser uma possibilidade de experimentação entre aquilo que se é e aquilo que pede passagem, impelindo à criação de

\footnotetext{
2 "O termo adolescente vem do latim adulescens, particípio presente do verbo adolescere, crescer; por sua terminação em esco, designa um processo e não um estado" (Rocheblave-Spenlé, 1995, p. 15).

${ }^{3}$ Mario Margulis e Marcelo Urresti (1998, p.10) falam do "capital temporal" característico da juventude: que "expresa simultaneamente una doble extensión , la distancia respecto del nacimiento y la lejanía respecto a la muerte."
} 
um novo corpo, um modo de ser, de sentir, de se relacionar. A adolescência deixou de ser, nesta experiência, uma faixa de idade, um período da vida pelo qual todos passam, para ser pensada como um devir que pode ser disparado nos encontros. A questão passou a ser como ativar em cada um seu devir-adolescente, a experiência de movência, a tentação nômade.

Neste contexto, as diferenças entre os participantes criaram solidariedade, afetividade e interesse e os vínculos no grupo se formaram com força e rapidez, impulsionando a pesquisa de formas de intervenção com grupos heterogêneos. (CANGUÇU et al., 2000). O recurso das atividades artísticas apresentou-se como estratégia potente para estimular e desenvolver a criação de diferentes formas de existência. A utilização do referencial das artes nos ajudou a buscar dimensões estéticas nas quais fosse possível realizar encontros de sutilezas, de diversidade que podia ser também diversão; de juntar em torno de um papel, várias e diferentes mãos e fazer surgir um trabalho, e ao mesmo tempo um corpo e um mundo diferente para cada um.

\section{ARTE CONTEMPORÂNEA E SAÚDE: AGENCIAMENTOS NA PRODUÇÃO DE SI E DO MUNDO}

O processo grupal levou a necessidade de um aprofundamento na pesquisa de linguagens e procedimentos artísticos que pudesse ampliar a oferta de recursos para o acompanhamento das poéticas que os participantes esboçavam. Assim, a partir do ano de 2002, uma artista plástica e arte-educadora - através da colaboração entre o Laboratório de Estudos e Pesquisa Arte, Corpo e Terapia Ocupacional e o MAC-USP - passou a integrar a equipe de coordenação, desde a concepção e o planejamento até a realização do projeto.

Juntos, artista, terapeutas ocupacionais e jovens (estudantes e participantes), começaram a arriscar um trabalho onde o aprendizado da arte através da experimentação e a possibilidade de criação se estendessem de modo efetivo a todos os participantes. A proposta se direcionou para a instauração de maior conexão entre o momento de trabalho corporal e o de trabalho plástico, buscando abordar o corpo na direção da experimentação plástica e trabalhar a matéria plástica no encontro com a experimentação corporal.

A articulação entre o corpo e as artes, a vida e a criação, levou aos trabalhos dos artistas Arthur Bispo do Rosário, Hélio Oiticica e Lygia Clark, eleitos como intercessores (DELEUZE, 1992) na instauração de um dispositivo de invenção artística e vital que pudesse afetar todos os envolvidos no processo e também aqueles que se encontravam no entorno dessa experimentação: familiares, amigos, outros terapeutas, alunos, e, quem sabe, alguns espectadores das artes.

As obras e trajetórias desses artistas dialogavam com o trabalho proposto ao colocar em questão o sistema da arte que eventualmente pode ou não defini-los como artistas ou como arte aquilo que fazem. Além disso, eles desenvolveram obras que possuem ressonâncias com o espaço clínico e habitaram uma zona de indiscernibilidade entre arte e clínica (ROLNIK, 1996) de maneira bem sucedida e com efeitos poderosos. O caráter estético de suas pesquisas, a exterioridade que instauram no sistema da arte e a desterritorialização que nele provocam nos inspirou a desenvolver um trabalho com arte de caráter experimental.

O trabalho de Lygia Clark encontra a obra no ato, na experiência que se vive em um fragmento de tempo. "É preciso - diz ela - absorver o sentido do precário para descobrir, na imanência do ato, o sentido da existência." (CLARK, 1997). Sua pesquisa poética levou-a ao limite do campo artístico e a fez desembocar numa região fronteiriça na qual arte e clínica estão implicadas em suas conexões, em suas dissonâncias, gerando um espaço de tensões que provoca desestabilização nos dois campos.

Bispo do Rosário, transitando entre a indigência e a loucura, passou grande parte de sua vida num manicômio, e foi submetido a um longo processo de exclusão. No entanto, a trajetória de Bispo mostra que ele criou, dentro do manicômio, agenciamentos que permitiram que a vida continuasse pulsando em seu corpo. Durante 40 anos, conseguiu escapar de choques-elétricos, lobotomias e medicação (dizendo que esta the minava a capacidade de trabalho) e proteger a si e a sua produção, construída fora de qualquer proposta terapêutica, por uma necessidade de tal intensidade que nem as amarras institucionais foram capazes de apaziguar. Produção que, como atestam alguns críticos de arte, dialoga de forma fecunda com a arte contemporânea. Além disso, nos chama a atenção a potência de seu processo criativo: ao lado do produto construído em anos de reclusão, vemos um produto imaterial, a própria vida que ali se fez (LIMA, 2003).

Por fim, Hélio Oiticica que equilibrando sua proposta poética nos "fios do experimental", entendido como "um ato cujo resultado é desconhecido" buscou em suas pesquisas, a radicalização de um estado de invenção, caminhando sempre entre a integração e a marginalidade relativamente ao sistema de arte. Seus projetos passaram cada vez mais a supor a ação do público, visado como realizador de 
propostas (FAVARETTO, 2000).

Inspirado nestes artistas, o trabalho daquele ano foi iniciado com a proposta de construção de objetos que pudessem conter coisas que os participantes trouxessem para o grupo. Essa idéia veio especialmente da observação de um dos participantes, talvez o mais desafiador. Possuía um corpo grande e forte com movimentos que raramente passavam despercebidos e que a cada ano crescia mais. Não falava, grunhia, berrava, urrava. Às vezes nos derruba e se derrubava, em seus movimentos impetuosos de quem pouco pôde experimentar as próprias pernas, fortes e mancas.

A cada encontro, trazia algo em suas mãos, na verdade, em uma de suas mãos, porque sofria de uma seqüela de paralisia cerebral, que era também, e sobretudo, uma seqüela de um sistema de saúde no qual nunca havia sido atendido sob a alegação da multiplicidade de seus desvios: deficiência física associada à deficiência mental, corpo de criança em tamanho de adulto.

Ele trazia estes objetos e insistia em pegar as bolsas que encontrava pela frente, abri-las, retirar o que tinha dentro e colocar o que trazia. Tomava as coisas que retirava das bolsas e depositava em continentes alheios ou os mantinha junto ao corpo. Nós por muitas vezes tivemos embates enormes para que ele pudesse devolver as coisas ao que considerávamos ser seus devidos lugares. Tudo isso parecia muito enigmático, pois pouco dizível em função do reduzido recurso das palavras e das nomeações. Quase poesia e quase nada.

$\mathrm{Na}$ tentativa de responder às inquietações provocadas por este e por outros participantes, começamos a pensar em procedimentos artísticos que pudessem comportar gestos, formas de expressão e experimentações que eram trazidas ao grupo. Entre eles, o procedimento de construção de continentes nos quais cada um dos integrantes do grupo pudesse carregar seus objetos escolhidos. Propomos, então, que os participantes trouxessem objetos variados para o grupo, ao mesmo tempo em que confeccionávamos, com tecidos, plásticos, estopas, roupas que se acoplassem ao corpo de cada um e ao corpo coletivo.

No entanto, raramente os participantes trouxeram objetos de casa. Por isso, resolvemos buscá-los no entorno de nosso espaço de trabalho, onde ocorreram algumas demolições que renderam objetos interessantes: escapamentos, pedaços de concreto e ferro, teclados de computador, frascos, latas. Materiais diversificados, entre eles alguns retirados ou destinados ao lixo; objetos que escapavam ao mundo, e que podiam retornar, acoplados a outros mundos.

Não se tratava de reciclagem, mas de um movimento de agenciamento com a matéria excedente no mundo, como um lugar de expressão do transbordamento que aqueles jovens viviam de maneiras singulares com suas deficiências, loucuras, fome, violência e riscos. Riscos de serem tratados também como matéria excedente, lançada ao lixo.

Novas perguntas passaram a conduzir nossa pesquisa estético-clínica: que potência de criação há no lixo? O que há de vida no que excede e transborda, no que não engata na lógica da utilidade? Que tipo de produção pode ser engendrada a partir desse excedente e que não pode restringir-se a servir para algo definido e definitivo?

Fernando Diniz, um dos artistas que trabalhou nos ateliês da Dra. Nise da Silveira tinha seu próprio ateliê no hospital, e apesar disso,

foi catar velhos lençóis no lixo, costurando-os e pintandoos com diversas camadas de tinta, até transformá-los em Tapetes Digitais, como os denominava (...) rebuscadas estruturações que têm como ponto de partida, segundo ele, sua própria mão, seus dedos (MELO, 2000, p. 43).

Os participantes do PACTO também conectavam suas mãos, seus dedos, a objetos que vinham das mais diversas procedências, num agenciamento no qual o lixo era o ponto de aglutinação de um fazer que transbordava o espaço do grupo em direção à vida.

Pouco a pouco, nos encontros, fomos aprofundando a conexão entre o corpo e seu fazer: trabalhamos com música experimental contemporânea e fizemos sons com bases de liquidificador, escovas, cabos de vassoura; dançamos com fitas e tramamos teias pela sala, lançando e cruzando fios que depois usávamos para tecer roupas; experimentamos procissões embrulhados em jornal; caminhamos por dentro de túneis feitos de sacos de lixo e materiais orgânicos, realizando passagens do escuro-fechado às frestas e à luz.

Como dizem Deleuze e Parnet (1998),

... é sempre sobre uma linha de fuga que se cria, não, é claro, porque se imagina ou se sonha, mas, ao contrário, porque se traça algo real, e compõe-se um plano de consistência. Fugir, mas fugindo, procurar uma arma (p.158).

Foi seguindo uma linha, caminhando sobre um fio, que encontramos estes objetos a partir do qual criávamos armas para a invenção de outros mundos, que nos desviavam do exercício artístico regrado, previsto, exigente na originalidade, impeditivo da invenção.

\section{CONCLUSÃO}

Dos encontros, em meio a tensões e embates, muitas produções emergiram. Esculturas, instalações, assemblages, objetos/vitrine, trajes, performances e práticas estéticas são nomeações possíveis para as materializações das quais nos 
aproximamos neste processo de experimentação. Toda a condução do grupo se deu em direção a modos particulares de relação com objetos do cotidiano e a novas ordenações destes materiais, de modo a propor um novo sentido para o olhar da própria vida.

Com esta proposta, possibilitamos aos jovens que acompanhávamos encontros, misturas e trocas que engendram novos circuitos e outras pertinências; buscamos a criação de uma nova sociabilidade e a experimentação de uma sensibilidade que possa despertar e acolher os desvios e as diferenciações, para que seja possível inventar trajetos e devires, passagens que facilitem processos de individuação psíquica, social e corporal. (DELEUZE, 1997) Processo de individuação entendido aqui como metaestável e autopoiético, compreedendo instabilidades e desequilíbrios (SIMONDON, 2003)

A proposta foi finalizada em 2003, com a construção de roupas, inspiradas nos parangolés de Hélio Oiticica e nos mantos de Bispo do Rosário. Bordamos, colamos, amarramos, costuramos, tecemos, emplastamos. Criamos mundos, uns leves, coloridos com fitas, e outros pesados de cola e massa de papel. Não tivemos a pretensão de que essas produções fossem consideradas objetos de arte, mas temos certeza de que estavam pareadas com as experimentações que levaram muitos artistas contemporâneos a radicalizar suas proposições poéticas em direção à vida.
Os resultados deste trabalho apontam para a construção de uma metodologia de intervenção na interface da TO com as artes, pautada pelo investimento no diálogo com experimentações artísticas contemporâneas, que pressupõe um alinhamento rigoroso entre criação artística e produção de vida e subjetividade.

Este diálogo possibilitou que a precariedade das vidas, dos processos, dos materiais alimentasse o questionamento do estatuto pré-definido da Arte elitizada e institucionalizada, e também o questionamento da Saúde entendida como normalidade e homogeneização que é, por vezes, impedimento da vivência singular e coletiva ao preconizar lugares e modos ideais e idealizados de fazer.

Se a TO pode ser um dos lugares privilegiados do olhar para o fazer, talvez possa ser do ponto de vista dos agenciamentos. "É isto agenciar: estar no meio, sobre a linha de encontro de um mundo interior e de um mundo exterior..." dizem Deleuze e Parnet (1998, p.66). Os autores nos dizem ainda que agenciar é a simpatia. "Mas a simpatia não é nada, é um corpo a corpo, odiar o que ameaça e infecta a vida, amar lá onde ela prolifera..." (DELEUZE; PARNET, 1998, p. 67).

Talvez este seja um aprendizado estético para a Terapia Ocupacional no encontro com as artes: esta simpatia que detecta e corrobora para que a vida prolifere, ainda que do lixo.

LIMA, E. M. F. de A.; CANGUÇU, D. F.; MORAES, C. INFORSATO, E. A. The youth group of PACTO: art and body on the invention of devices in occupational therapy to the production of life and health in adolescence. Rev. Ter. Ocup. Univ. São Paulo, v. 20, n. 3, p. 157-163, set./dez. 2009.

\begin{abstract}
This article's aim is to present the work developed on the youth group of PACTO - Artistic Compositions and Occupational Therapy Program -, a field of experimentation and research in group intervention with people coming from different social and economic realities, and presenting multiple problematic. The analysis focus on the proposal developed in 2002 and 2003, when occupational therapists, visual artists and art-educators were involved on generating the concept, planning and inventing a device that could improve life and health projects for the people assisted, bringing a wider vision to the accompaniment of singular trajectories. The result of this work point out the construction of aim of the research developed with this group was to construct a methodology of intervention in the art and occupational therapy interface that presupposes a rigorous articulation between artistic creation and production of subjectivity. Trough a dialogue with contemporary art, this methodology explores particulars ways of relating with every-day objects in the search to experiment news meanings to look life itself.
\end{abstract}

KEY WORDS: Occupational therapy/trends. Art. Art therapy/trends. Adolescent. 
LIMA, E. M. F. de A.et al. PACTO Adolescentes: arte e corpo. Rev. Ter. Ocup. Univ. São Paulo, v. 20, n. 3, p. 157-163, set./dez. 2009.

\section{REFERÊNCIAS}

BARROS, R. B. Dispositivos em ação: o grupo. In: LANCETTI, A. (org.). Saúde e loucura 6: subjetividade. São Paulo: Hucitec, 1997.

CANGUÇU, D. F.; CASTRO, E. D.; COSTA, A. L. B.; INFORSATO, E. A.; LIMA, E. A.; LIMA, L. J. C. Programa Permanente de Composições Artísticas e Terapia Ocupacional (PACTO): uma proposta de Atenção na Interface Arte-Saúde. Rev. Ter. Ocup. Univ. São Paulo, v. 11, n. 2/3, p. 45-55, 2000.

CLARK, L. Textos e escritos. Barcelona: Fundació Antoni Tápies, 1997. Catálogo.

CUBIDES, H. J. C.; TOSCANÃO, M. C. L.; VALDERRAMA, C. E. (orgs.) Viviendo a toda: jóvenes, territorios culturales y nuevas sensibilidades. Santa Fé de Bogota : Fundación Universidad Central, 1998.

DELEUZE, G. Crítica e clínica. São Paulo: Ed. 34, 1997.

DELEUZE, G. Conversações. Rio de Janeiro: Ed. 34, 1992.

DELEUZE, G.; PARNET, C. Diálogos. São Paulo: Ed. Escuta, 1998.

DELEUZE, G.; GUATTARI, F. Micropolítica e segmentariedade. In: Mil platôs, v. 3. São Paulo: Ed. 34, 1996.

DOLTO, F. A causa dos adolescentes. Rio de Janeiro: Ed. Nova Fronteira, 1990.

FAVARETTO, C. A invenção de Hélio Oiticica. São Paulo: Fapesp/ Edusp, 2000.

FREUD, A. Adolescência. Rev. Assoc. Psicanal. Porto Alegre: Adolescência, n.11, nov 1995.

GUATTARI, F. Práticas ecosóficas e restauração da cidade subjetiva. Trad. Andrea Morais Alves. Tempo Brasileiro, Rio de Janeiro, v. 116, p. 9-26, jan/mar 1994.

HIDALGO, L. Arthur Bispo de Rosário: o senhor do labirinto. Rio de Janeiro: Rocco, 1996.

LIMA, E. M. F. A. Das obras aos procedimentos: ressonâncias entre os campos da Terapia Ocupacional e das Artes. São Paulo, 2003. 346 f. Tese (Doutorado). Programa de Estudos PósGraduados em Psicologia Clínica da PUC/SP. São Paulo, 2003.

MARGULIS, M.; URRESTI, M. La construcción social de la condición de la juventud. In: Viviendo a toda: jóvenes, territorios culturales y nuevas sensibilidades. Santa Fé de Bogotá: Fundación Universidad Central, 1998.

MELLO, L. C. Flores do abismo. In: Associação Brasil 500 anos Artes Visuais. Imagens do Inconsciente (catálogo da Mostra do redescobrimento). São Paulo, 2000.

RASSIAL, J. J. Hipóteses sobre a adolescência. Rev. Assoc. Psicanal. Porto Alegre: Adolescência, n.11, nov 1995.

ROLNIK, S. Lygia Clark e o híbrido arte-clínica. Rev. Percurso, v. 16, n. 1, p. 43-48, 1996.

ROCHEBLAVE-SPENLÉ, A. M. O adolescente e seu mundo. São Paulo: Livraria Duas Cidades, 1995.

RUFINO, R. Adolescência: notas em torno de um impasse. Rev. Assoc. Psicanal. Porto Alegre: Adolescência, n.11, nov 1995.

SIMONDON, G. A gênese do indivíduo. Cadernos de subjetividade: o reencantamento do concreto. São Paulo: Hucitec, 2003.

TAVARES, E. E. O futuro de uma esperaça. Rev. Assoc. Psicanal. de Porto Alegre: Adolescência, n.11, nov 1995. 